\title{
A fast-switching light-writable and electric-erasable negative photoelectrochromic cell based on Prussian blue films
}

\author{
Zhihui Jiao $^{\mathrm{a}}$, Jun Ling Song ${ }^{\mathrm{b}}$, Xiao Wei Sun ${ }^{\mathrm{a}, \mathrm{c}, *}$, Xue Wei Liu ${ }^{\mathrm{b}}$, Jin Min Wang ${ }^{\mathrm{a}}$, Lin Ke ${ }^{\mathrm{d}}$, \\ Hilmi Volkan Demir ${ }^{\text {a,b,e }}$ \\ a School of Electrical and Electronic Engineering, Nanyang Technological University, Nanyang Avenue, Singapore 639798, Singapore \\ ${ }^{\mathrm{b}}$ School of Physical and Mathematical Sciences, Nanyang Technological University, Nanyang Avenue, Singapore 637371, Singapore \\ ${ }^{\mathrm{c}}$ Department of Applied Physics, College of Science, Tianjin University, Tianjin 300072, China \\ ${ }^{\mathrm{d}}$ Institute of Material Research and Engineering, 3 Research Link, Singapore 117602, Singapore

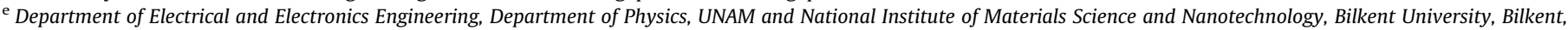 \\ Ankara 06800, Turkey
}

\section{A R T I C L E I N F O}

\section{Article history:}

Received 25 July 2011

Accepted 21 October 2011

\section{Keywords:}

Photoelectrochromic

Prussian blue

Nanocrystalline $\mathrm{TiO}_{2}$

Response time

\begin{abstract}
A B S T R A C T
We report a fast-switching negative photoelectrochromic cell composed of a dye-sensitized nanocrystalline $\mathrm{TiO}_{2}$ electrode and Prussian blue counter electrode sandwiching a Lil electrolyte. The cell can be bleached under illumination with shorted $\mathrm{TiO}_{2}$ and Prussian blue electrodes, and re-colored by applying an appropriate external voltage. The photo-bleaching and electric-coloring processes are fast and reversible. A maximum absorbance modulation of 0.44 recorded at $700 \mathrm{~nm}$ is obtained between bleached and colored states for the cell when the PB film's thickness is $452 \mathrm{~nm}$. Illuminated under different levels of light intensity or durations of time, the shorted cell shows adjustable optical absorption from 470 to $840 \mathrm{~nm}$. The in-situ transmittance response depicts that the photo-bleaching response is $6.2 \mathrm{~s}$ for $70 \%$ transmittance change under $100 \mathrm{~mW} / \mathrm{cm}^{2}$ illumination in short circuit configuration, and the re-coloration time is about $600 \mathrm{~ms}$ under $2 \mathrm{~V}$ bias recorded at $780 \mathrm{~nm}$, with an electrochromic coloration efficiency of $103.4 \mathrm{~cm}^{2} / C$. The cell shows a good reversible stability and can be potentially applied in erasable displays.
\end{abstract}

(c) 2011 Elsevier B.V. All rights reserved.

\section{Introduction}

In recent years, the growing interest in low-power systems has led to the development of various energy-efficient chromic technologies including electrochromism, photochromism, gaschromism, thermalchromism, and photoelectrochromism [1-16]. Among them, photoelectrochromic devices have attracted significant attention because of their unique function of dynamically controlled solar energy gain and optical properties through switchable glazing in response to illumination, with promising applications in smart windows, sunglasses and light-writable low-information content displays [11,12,17,18]. Although various device configurations and working mechanisms have been reported in recent years [11,19-21], most of the reported photoelectrochromic devices are composed of a light-sensitive photovoltaic layer and an electrochromic layer. A dye-sensitized $\mathrm{TiO}_{2}$

\footnotetext{
* Corresponding author at: School of Electrical and Electronic Engineering, Nanyang Technological University, Nanyang Avenue, Singapore 639798, Singapore. Tel.: + 65 67905369; fax: +65 67933318 .

E-mail address:

exwsun@ntu.edu.sg (X.W. Sun).
}

nanoparticle (NP) photoanode has been most commonly adopted as the photovoltaic layer, and various electrochromic materials (inorganic or organic) have been assembled as the electrochromic electrode including $\mathrm{WO}_{3}$ or polyaniline $[11,12,22,23]$. Under illumination, photoelectrons generated by the dye molecule inject into the conduction band of $\mathrm{TiO}_{2}$ and then transport through the external circuit to the counter electrochromic electrode, driving the ions in the electrolyte to intercalate into the electrochromic layer at the same time. Correspondingly, the transmittance of the photoelectrochromic device will be decreased as a result of the darkened electrochromic layer. The bleaching state can be achieved by either short circuit or open circuit configuration with light blocked. The switching response is mainly dependent on the electrochromic material and electrode adopted. Recently, Chen's group improved the bleaching rate of a $\mathrm{WO}_{3}$-based photoelectrochromic device using a patterned $\mathrm{WO}_{3} / \mathrm{Pt}$ electrode, providing the charge transfer pathways to accelerate the bleaching process [22]. Under illumination, the cell can be colored in a short circuit configuration with tunable transmittance and bleached more quickly when the circuit is opened $(\sim 60 \mathrm{~s})$.

Prussian blue [PB, iron (III) hexacyanoferrate (II)] is a well known synthetic coordination-compounded transition metal 
hexacyanometallate, which has attracted considerable attention owing to its various applications in electrochromic [24-26], sensors [27], catalysts [28], and batteries [29]. Different from $\mathrm{WO}_{3}, \mathrm{~PB}$ is an anodically coloring electrochromic material with promising electrochromic properties. It is reported that an electrodeposited PB film exhibits electrochromism between blue and colorless state with a fast response $(\leq 100 \mathrm{~ms})$ and a high durability for $5 \times 10^{6}$ cycles [30]. The excellent electrochromic performance makes it an ideal candidate for applications in smart windows and electronic paper displays. Although there have been numerous reports regarding electrochromic applications of $\mathrm{PB}$, to our knowledge, such a PB film has not been incorporated in a device to enable fast-switching light-writable and electric-erasable photoelectrochromic operation to date.

In this study, we propose and demonstrate a negative photoelectrochromic cell, composed of an electrodeposited PB electrochromic electrode and a dye-sensitized $\mathrm{TiO}_{2} \mathrm{NP}$ photoanode. The cell can be bleached in short circuit configuration under illumination and re-coloration can be achieved through applying a proper external voltage with fast switching response and good reversibility, providing a negative mode to the existing photoelectrochromic technology. The bleached cell can also be recolored in either short circuit under dark state or open circuit under illumination with a slow speed. The photoelectrochromic cell shows obvious color change between colored and bleached state, promising for light-writable and electric-erasable information display applications.

\section{Experimental details}

\subsection{Electrodeposition and characterization of $P B$ films}

Fluorine doped tin oxide $\left(\mathrm{SnO}_{2}: \mathrm{F}\right.$, FTO) glasses (NSG Group, $R_{s}=14 \Omega / \square$ and $2.2 \mathrm{~mm}$ thick) washed by acetone, isopropanol, and de-ionized water in sequence were used as substrates. The electrodeposition of PB films was carried out in a standard three-electrode system (VersaSTAT 3F Potentiostat/Galvanostat) with a clean FTO glass $(2 \mathrm{~cm} \times 3 \mathrm{~cm})$ as the working electrode, a platinum sheet as the counter electrode, and a $\mathrm{Ag} / \mathrm{AgCl} / \mathrm{sat}$ 'd $\mathrm{KCl}$ as the reference electrode. The electrodeposition bath of PB contained $10 \mathrm{mM} \mathrm{K}{ }_{3} \mathrm{Fe}(\mathrm{CN})_{6}$ (Aldrich), $10 \mathrm{mM} \mathrm{FeCl}_{3}$ (Aldrich), and $0.1 \mathrm{M} \mathrm{KCl}$ (Aldrich). The PB films were prepared by applying a constant cathodic current density of $50 \mu \mathrm{A} / \mathrm{cm}^{2}$ for $100,300,500$ and $700 \mathrm{~s}$. Then the as-deposited blue PB films was rinsed by deionized water gently and dried at room temperature in atmosphere.

\subsection{Preparation of dye-sensitized $\mathrm{TiO}_{2}$ nanocrystalline photoanode}

To fabricate the photoanode, $\mathrm{TiO}_{2}$ NP paint (Solaronix, Ti-Nanoxide T20/SP) was first screen-printed on a piece of FTO glass, which was ultrasonically cleaned sequentially by acetone, isopropanol, and de-ionized water. After calcination at $450{ }^{\circ} \mathrm{C}$ for $1 \mathrm{~h}$, a transparent and well adhesive $\mathrm{TiO}_{2}$ film with a thickness of $\sim 4 \mu \mathrm{m}$ was obtained. Dye absorption was carried out by immersing the $\mathrm{TiO}_{2}$ electrode into a Z907 solution [(cis-bis(isothiocyanato)(2,2'-bipyridyl-4,4'-dicarboxylato)(4,4'-di-nonyl-2'-bipyridyl)ruthenium(II)) in dilute $(8 \mu \mathrm{M})$ ethanol solution containing $60 \mathrm{mM}$ chenodeoxycholic acid] for $110 \mathrm{~min}$. The electrode was then washed with acetonitrile for 3 times to remove the unanchored dye molecules. The dye coverage was kept low to make the cells semi-transparent in the "off" state.

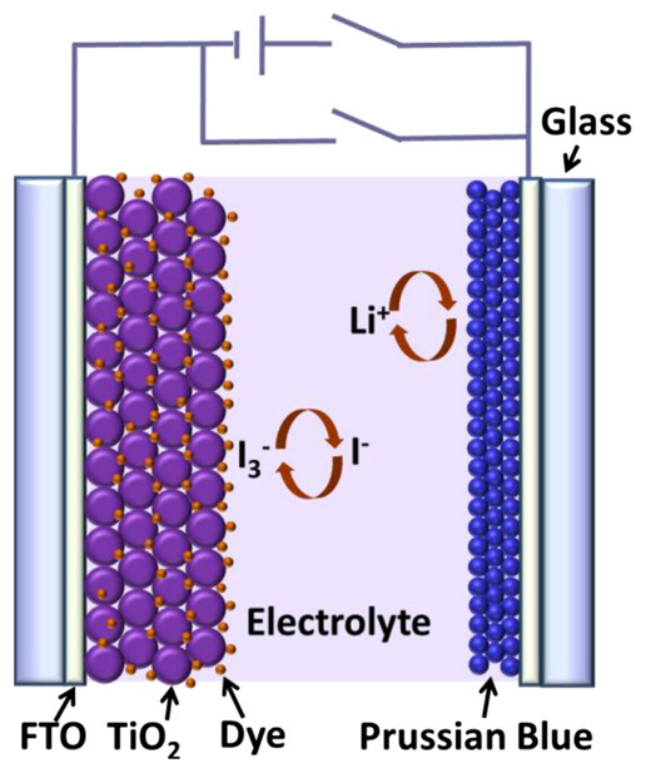

Fig. 1. Schematic of the proposed hybrid photoelectrochromic cell.

\subsection{Assembly of the photoelectrochromic cell}

The dye-sensitized $\mathrm{TiO}_{2}$ nanocrystalline photoanode and $\mathrm{PB}$ electrode were bonded together with hot-melt Surlyn spacers. Then a liquid electrolyte solution composed of $0.1 \mathrm{M} \mathrm{Lil}$ and $0.01 \mathrm{M}$ 4-t-butylpyridine in $\gamma$-butyrolactone was introduced between the two electrodes by capillary action. Finally the cell was sealed with epoxy. The final cell has a configuration of

\section{FTO $\mid \mathrm{TiO}_{2}$ (dye) $\mid$ LiI + 4-t-butylpyridine $\mid$ PB $\mid$ FTO}

which is also schematically shown in Fig. 1.

\subsection{Characterization}

The morphologies of electrodeposited PB films were characterized by field emission scanning electron microscopy (FESEM JSM 6340F). Cyclic voltammogram (CV) of the PB film was performed with $0.2 \mathrm{M} \mathrm{LiClO}_{4}$ in $\gamma$-butyrolactone as the electrolyte, a platinum sheet as the counter electrode and $\mathrm{Ag} / \mathrm{AgCl} / \mathrm{sat}$. $\mathrm{KCl}$ as the reference electrode. Thicknesses of the PB films were measured by a Tencor P-10 surface profiler. The transmittance was measured by a JASCO V670 UV-vis-NIR spectrophotometer. A $150 \mathrm{~W}$ Xe lamp with optical filter ( $>300 \mathrm{~nm}$ ) was used as the light source and the light intensity was calibrated by a pyranometer (PMA 2144 from Solar Light)

\section{Results and discussion}

\subsection{Characterization of electrodeposited PB films}

The morphologies of electrodeposited PB films were investigated (see Fig. 2a). It can be clearly seen from Fig. 2(a) that the film is composed of accumulated nanoparticles with sizes of 20-50 $\mathrm{nm}$. There are a lot of cracks with an average gap dimension of $\sim 20 \mathrm{~nm}$ among the film, formed due to stress. The cyclic voltammetry (CV) curve of the PB film was measured with $0.2 \mathrm{M}$ $\mathrm{LiClO}_{4}$ in $\gamma$-butyrolactone as electrolyte at a scan rate of $100 \mathrm{mV} / \mathrm{s}$ (Fig. 2b). The broad oxidation and reduction peaks appear at 0.84 and $-0.8 \mathrm{~V}$, respectively, which are similar to those reported for 

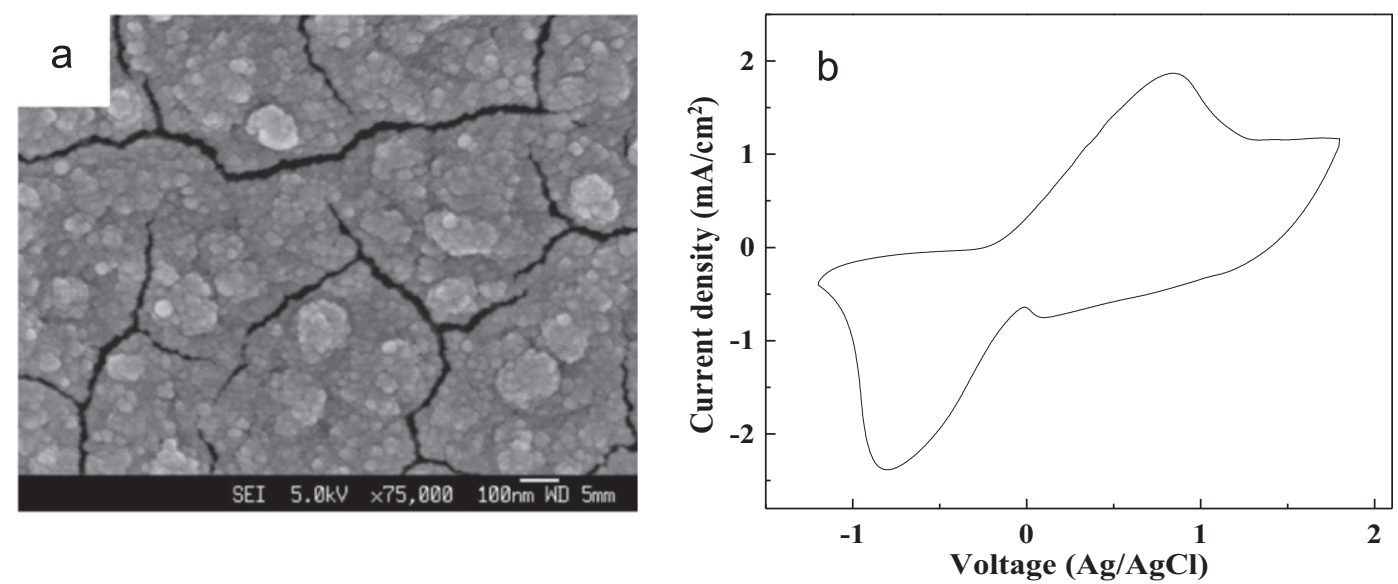

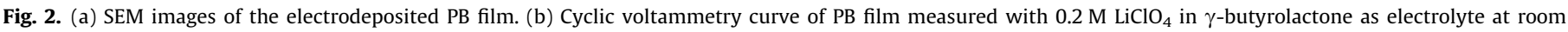
temperature with a scan rate of $100 \mathrm{mV} / \mathrm{s}$ from -1.2 to $1.7 \mathrm{~V}$.

electrodeposited PB films [30]. During the cycling, the color of the PB film was observed to change between blue and colorless.

\subsection{Working principles of the photoelectrochromic cell}

It is well known that PB is an anodically electrochromic material, opposite to $\mathrm{WO}_{3}$, which is colored cathodically. Due to the opposite electrochromic behaviors of $\mathrm{PB}$ and $\mathrm{WO}_{3}$, the asprepared cell is bleached rather than colored under illumination in short circuit configuration, providing a negative mode of the existing photoelectrochromic technology $[11,12]$. Under illumination, light absorption by the sensitizing dye leads to electron injection into the conduction band of $\mathrm{TiO}_{2}$ and then transport through external circuit to the counter $\mathrm{PB}$ electrode, driving the insertion of $\mathrm{Li}^{+}$from the electrolyte into the PB film at the same time. Accordingly, the color of the PB film changes from blue to colorless, which can be described by the following reaction:

$$
\begin{aligned}
& \mathrm{Fe}(\mathrm{III})_{4}\left[\mathrm{Fe}(\mathrm{II})(\mathrm{CN})_{6}\right]_{3}(\mathrm{~PB}, \text { blue })+4 \mathrm{e}^{-}+4 \mathrm{Li}^{+} \\
& \leftrightarrow \mathrm{Li}_{4} \mathrm{Fe}(\mathrm{II})_{4}\left[\mathrm{Fe}(\mathrm{II})(\mathrm{CN})_{6}\right]_{3}(\text { colorless })
\end{aligned}
$$

At the same time, the excited dye molecules are reduced by iodide ion $\left(\mathrm{I}^{-}\right)$present in the electrolyte according to the reaction [31]:

$2 \mathrm{~S}^{+}+3 \mathrm{I}^{-} \rightarrow 2 \mathrm{~S}^{0}+\mathrm{I}_{3}^{-}$

where $\mathrm{S}^{0}$ and $\mathrm{S}^{+}$are the ground and ionized state of the dye molecule, respectively. The photo-bleaching process terminates when all $\mathrm{I}^{-}$in the electrolyte are transformed to triiodide $\left(\mathrm{I}_{3}^{-}\right)$or until the generated photovoltage equals the electromotive force of the formed $\mathrm{Li}_{4} \mathrm{Fe}(\mathrm{II})_{4}\left[\mathrm{Fe}(\mathrm{II})(\mathrm{CN})_{6}\right]_{3}$ film, preventing the further diffusion of the electrons into the EC layer.

Fig. 3(a) schematically depicts the photo-bleaching process of the short circuit photoelectrochromic cell under illumination from the side of dye-sensitized $\mathrm{TiO}_{2}$ NP photoanode. The color of PB film changes from original blue to colorless, resulting from the insertion of $\mathrm{Li}^{+}$and electrons, while the iodide ions are oxidized to triiodide by the excited dye molecules at the electrolyteldye interface. Fig. 3(b) shows the photograph of a bleached photoelectrochromic cell $\left(1.5 \mathrm{~cm}^{2}\right)$ after illumination of $100 \mathrm{~mW} / \mathrm{cm}^{2}$ for $1 \mathrm{~min}$ in short circuit configuration. The PB film assembled in the cell is electrodeposited for $300 \mathrm{~s}$ and its thickness is measured to be $452 \mathrm{~nm}$. It can be seen that the original blue color of the PB film changes to colorless and the bleached cell displays pale yellow arising from the dye molecules absorbing on the surface of $\mathrm{TiO}_{2}$ electrode. The photovoltaic property of the cell was also investigated and shown
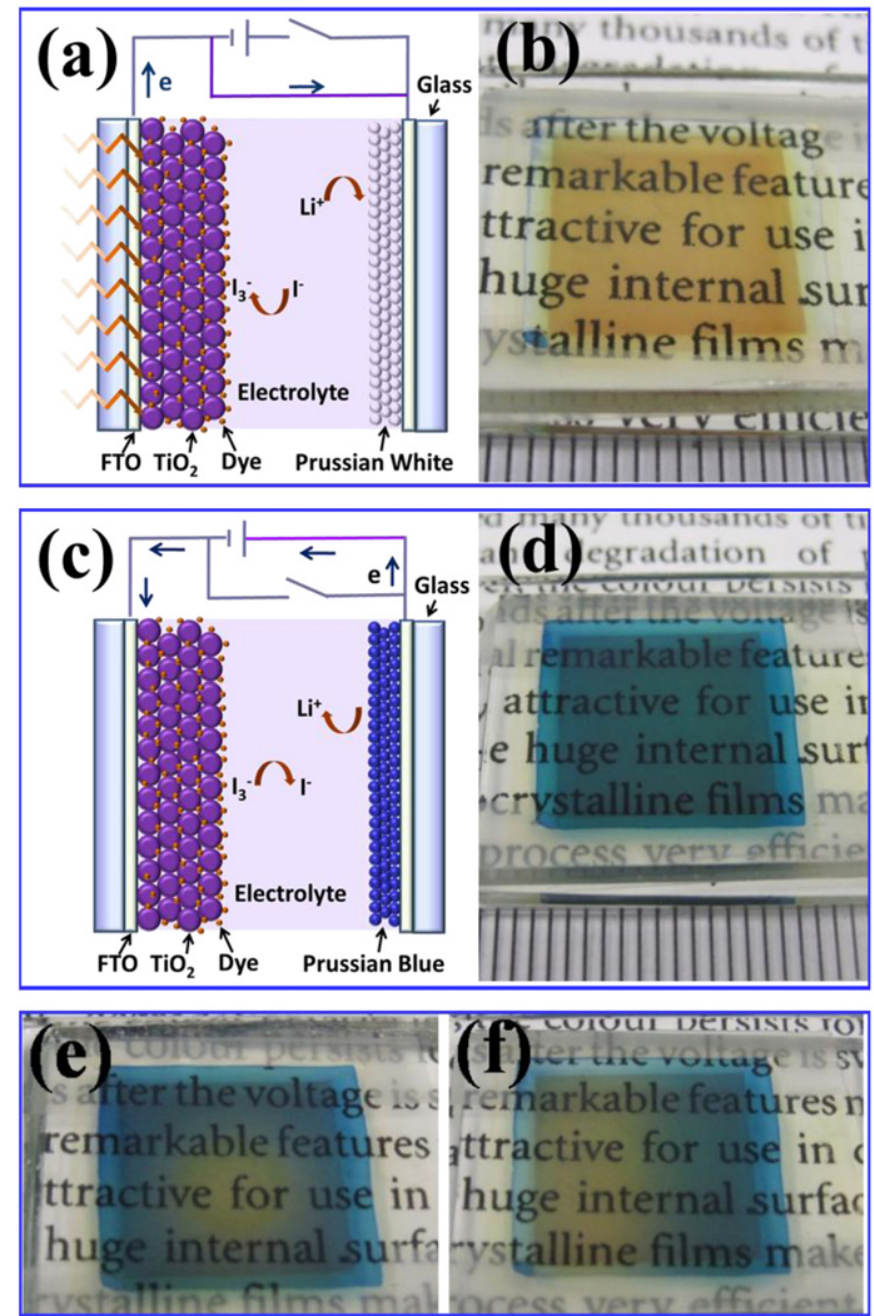

Fig. 3. Schematics and photographs of a photoelectrochromic cell with a $1.5 \mathrm{~cm}^{2}$ active area. The duration for electrodeposition of PB film is $300 \mathrm{~s}$. (a) Schematic of the short circuit cell under illumination for bleaching. (b) Bleached cell achieved by illumination of $100 \mathrm{~mW} / \mathrm{cm}^{2}$ for 1 min in short circuit configuration. (c) Schematic of the cell under external voltage for coloring. (d) Photograph of the cell at colored state after applying a $2 \mathrm{~V}$ bias at PB electrode for $30 \mathrm{~s}$. (e, f) Spatially resolved bleaching states achieved by illuminating the cell with masks. 
in Fig. S1. An open circuit voltage $\left(V_{\text {oc }}\right)$ of $0.42 \mathrm{~V}$ and a short circuit current $\left(I_{\mathrm{sc}}\right)$ of $1.15 \mathrm{~mA} / \mathrm{cm}^{2}$ are obtained for this cell. The fill factor $(\mu)$ is calculated to be 0.54 .

The re-coloration process was carried out by applying a positive $2 \mathrm{~V}$ bias on $\mathrm{PB}$ electrode (while $\mathrm{TiO}_{2}$ side is grounded) until the current density was stabilized, during which $\mathrm{Li}^{+}$was driven out from PB film to the electrolyte, leaving PB in blue. At the same time, triiodide ions at the counter electrode were reduced to iodide ions by the electrons injected from the external bias:

$\mathrm{I}_{3}^{-}+2 \mathrm{e}^{-} \rightarrow 3 \mathrm{I}^{-}$

In this way, triiodide ions are produced during the photo-bleaching process and are reduced back to iodide ions during the re-coloration process at the dye/electrolyte interface.

In fact, the re-coloration of the cell can also be achieved in either short circuit under dark or open circuit with or without illumination. The charged $\mathrm{Li}_{4} \mathrm{Fe}(\mathrm{II})_{4}\left[\mathrm{Fe}(\mathrm{II})(\mathrm{CN})_{6}\right]_{3}$ electrode possesses a negative potential, which causes the cell to discharge spontaneously back to its colored state. However, the re-coloration without external bias shows a much slower speed. It needs about $\sim 2 \mathrm{~h}$ to complete the re-coloration process of the opencircuited cell under illumination. The short-circuited cell shows a faster re-coloration speed than the open-circuited one, since the electrons can transport to the counter electrode through external circuit more efficiently, while the electrons in open circuit configuration are extracted from the EC layer and undergo a diffusion process to counter electrode. However, it still needs more than one hour for the re-coloration in short circuit configuration. To reach a fast and efficient re-coloration, a proper external bias is adopted to overcome this problem.

To obtain good reversible stability, charges, and ions involved in the two processes should be balanced. Correspondingly, an optimum bias voltage should be adopted since a too large bias will lead to over oxidization of PB to Prussian White (PW), while a too small bias results in insufficient re-coloration and slow response. For our cells, $2 \mathrm{~V}$ bias was adopted for re-coloration and, as a result, a fast response and good stability were achieved. Fig. 3(c) shows the schematic of the re-coloration process and Fig. 3(d) depicts the photograph of the cell after applying a positive $2 \mathrm{~V}$ bias on $\mathrm{PB}$ electrode for $30 \mathrm{~s}$. It can be seen that the PB film changes to its original blue color reversibly after applying an electric stimuli. Moreover, spatially resolved bleaching was achieved when the cell was partially illuminated (Fig. 3e and f). The spatially resolved bleaching occurs because the electric field is created spatially in the illuminated region; i.e., the electric field is concentrated between the oxidized dye and reduced PB counter electrode. However, the resolution of such spatially resolved bleaching is limited as such the electric field is maintained by ion diffusions. The above results indicate the prepared photoelectrochromic cells can be potentially applied in negative mode light-writable and electric-erasable information displays.

\subsection{Optical-electro characterizations of the photoelectrochromic cell}

It is clear that longer duration of electrodeposition will lead to thicker PB films with a deeper blue color. Since the bleached PB films remain highly transparent, for single PB electrochromic layer device, larger optical modulation (absorbance or transmittance) could be obtained using a thicker film. However, for thicker films, a larger operating voltage is needed for complete coloration/bleaching processes. To investigate the thickness effect on the optical modulation between bleached and colored states of the photoelectrochromic cells, PB films with electrodeposition durations of 100, 300, 500 and $700 \mathrm{~s}$ were assembled as electrochromic layers into the cells. The thicknesses of all the electrodeposited PB films were measured and tabulated in Table 1. For all the cells, the conditions of dye-sensitized
Table 1

Photoelectrochromic cells with different thicknesses of PB films and corresponding absorbance modulation at $700 \mathrm{~nm}$.

\begin{tabular}{llcl}
\hline Type & Duration $(\mathrm{s})$ & Thickness $(\mathrm{nm})$ & Absorbance modulation \\
\hline A & 100 & 123 & 0.20 \\
B & 300 & 452 & 0.44 \\
C & 500 & 785 & 0.24 \\
D & 700 & 1106 & 0.13 \\
\hline
\end{tabular}

$\mathrm{TiO}_{2}$ nanocrystalline photoanode and electrolyte were fixed. Subsequently, all the cells were bleached by illumination at $100 \mathrm{~mW} / \mathrm{cm}^{2}$ for $1 \mathrm{~min}$ in short circuit configuration and re-colored by a positive $2 \mathrm{~V}$ bias on the PB electrode for $30 \mathrm{~s}$. Optical absorbance spectra were investigated for all cells at the two states (Fig. 4). It can be seen from Fig. 4 that with increased PB film thickness, the absorbance of all cells at the colored state are enhanced from 470 to $840 \mathrm{~nm}$. Also, the absorbance of all cells at the bleached state is obviously decreased compared to its colored state. Moreover, with PB film thickness increased from 123 to $452 \mathrm{~nm}$, the absorbance modulations recorded at $700 \mathrm{~nm}$ between the two states are increased from 0.2 to 0.44 . However, the modulation was decreased to 0.24 and 0.13 when the film thickness was further increased to 785 and $1106 \mathrm{~nm}$, respectively, resulting from the insufficient bleaching. For our photoelectrochromic cells, the photogenerated voltage $(\sim 0.4 \mathrm{~V})$ is fixed under the same light intensity, and a too thick film will result in shallow bleaching level of PB film due to insufficient operating voltage and increased resistance. As shown in Fig. 4(b), the largest absorbance modulation $(0.44)$ recorded at $700 \mathrm{~nm}$ was obtained when the $\mathrm{PB}$ film thickness is set to $452 \mathrm{~nm}$. The corresponding transmittance of the cell under this optimum condition is shown in Fig. S2 for reference. Compared with the colored states, the absorbance of all cells at the bleached states are increased in the spectral range of 400$470 \mathrm{~nm}$, which may be attributed to the absorption of triiodide ions formed at the dyelelectrolyte interface. In the following part, we fix the thickness of PB film at the optimal value (452 nm). Following the standard test method of ASTM D1003A [32,15], the haze numbers of the cell at bleached state were investigated and shown in Fig. S3. It can be seen that the haze number increases with decreasing wavelength, which is due to the scattering losses caused by the $\mathrm{TiO}_{2}$ nanoparticle becomes increasingly pronounced [15]. The luminous transmittance $\left(T_{\text {lum }}\right)$ of the bleached device recorded from 400 to $850 \mathrm{~nm}$ is calculated to be $42 \%$, and the luminous transmittance ( $T_{\text {lum }}$ ) of the colored device is $18 \%$, which corresponds to a contrast ratio of 2.3. The ratio is smaller than that of the commercial electrochromic devices, which is normally larger than 3:1 [33,34]. More work is being done now to further decrease the thickness of the $\mathrm{TiO}_{2}$ nanoparticle electrode to improve the contrast ratio between bleached and colored state of the device.

To further investigate the impact of light intensity on its absorbance, the cell was illuminated with simulated solar illumination of $5,10,20,30,40,50$, and $100 \mathrm{~mW} / \mathrm{cm}^{2}$, respectively for a fixed duration ( $3 \mathrm{~s}$ ) in short circuit configuration (Fig. 5a). It can be seen that with increased light intensity, the absorbance decreases gradually from 470 to $840 \mathrm{~nm}$. Moreover, the absorbance decreases significantly in $3 \mathrm{~s}$ between 10 and $50 \mathrm{~mW} / \mathrm{cm}^{2}$, and from 50 to $100 \mathrm{~mW} / \mathrm{cm}^{2}$, the decrease is comparatively less, indicating adjustable absorption of the cell under different levels of light intensity (grayscale is obtainable). Fig. 5(b) shows the absorbance spectra after $5,10,15,20,25,30$, and $60 \mathrm{~s}$ of illumination with a fixed simulated solar intensity of $5 \mathrm{~mW} / \mathrm{cm}^{2}$. It can be seen that the absorbance decreases with prolonged illumination time from 470 to $840 \mathrm{~nm}$, and the decrease is mostly completed in $25 \mathrm{~s}$, after which the decrease is not obvious. For both cases, there is not much difference of absorbance below $470 \mathrm{~nm}$, indicating the cell mainly regulates the absorbance in the visible range. Thus the absorbance of 

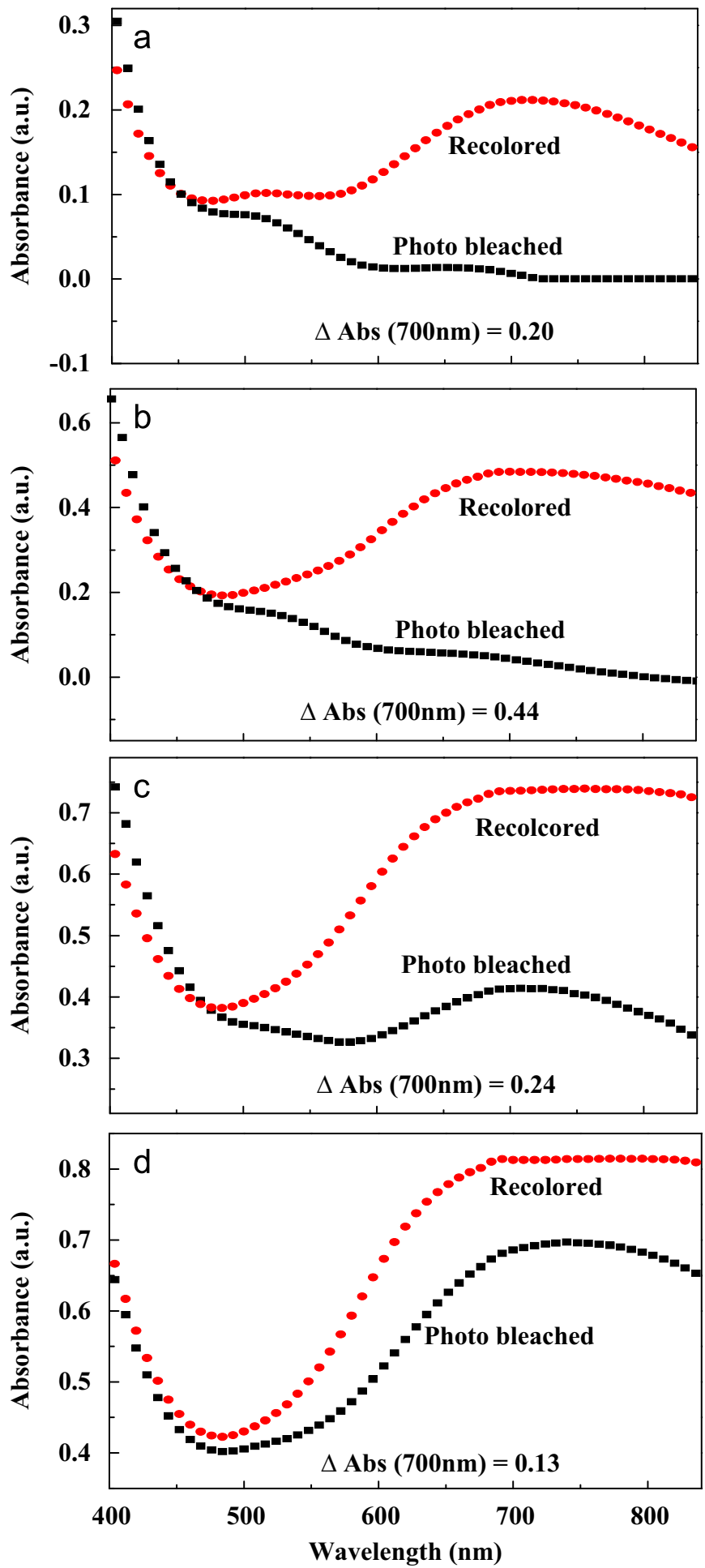

Fig. 4. Absorbance spectra of the phtotoelectrochromic cell at bleached state by illumination with a simulated solar intensity of $100 \mathrm{~mW} / \mathrm{cm}^{2}$ for $1 \mathrm{~min}$ and colored state by applying a $2 \mathrm{~V}$ bias at the PB electrode for $30 \mathrm{~s}$. The PB films assembled in these cells were electrodeposited for (a) $100 \mathrm{~s}$, (b) $300 \mathrm{~s}$, (c) $500 \mathrm{~s}$ and (d) $700 \mathrm{~s}$.

the cell in the visible light range can be adjusted with either light intensity or illumination time.

The photo-bleaching response of the cell was investigated at a wavelength of $780 \mathrm{~nm}$ by $100 \mathrm{~mW} / \mathrm{cm}^{2}$ illumination in short circuit configuration (shown in Fig. 6a). The response for $70 \%$ change is found to be $6.2 \mathrm{~s}$. Inset of Fig. 6(a) depicts the corresponding transient current change of the cell from the colored to a

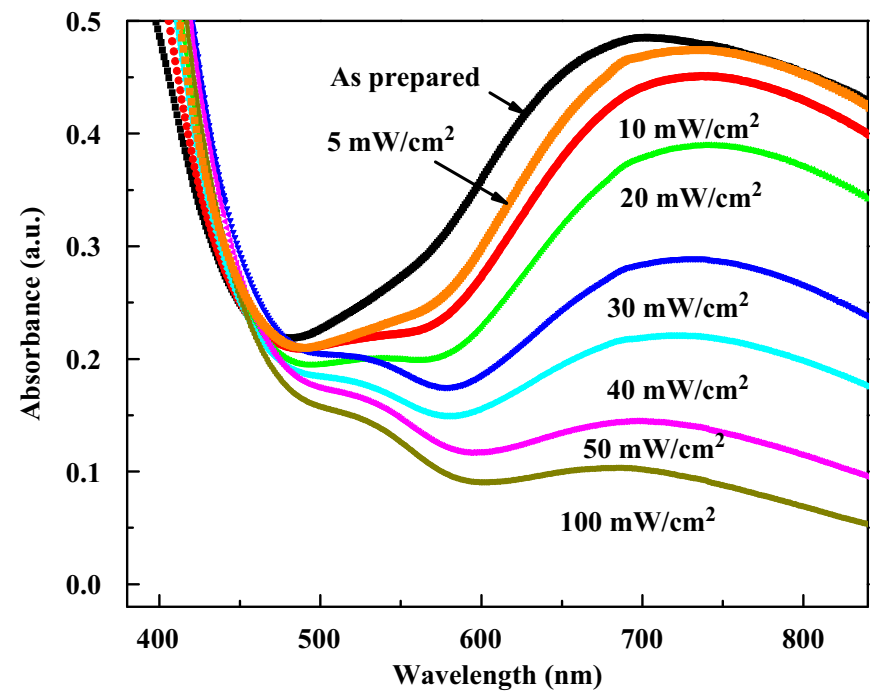

b

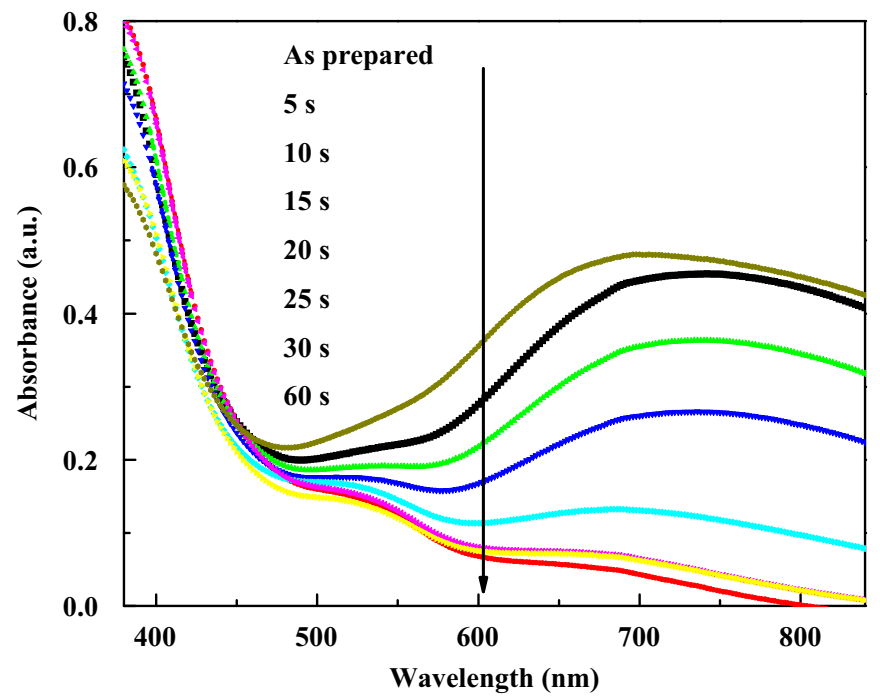

Fig. 5. (a) Absorbance spectra of the as-prepared cell and illuminated with simulated light intensity levels of $5,10,20,30,40,50$, and $100 \mathrm{~mW} / \mathrm{cm}^{2}$ for $3 \mathrm{~s}$ in short circuit configuration. (b) Absorbance spectra of the as-prepared cell and illuminated with $5 \mathrm{~mW} / \mathrm{cm}^{2}$ for $5,10,15,20,25,30$, and $60 \mathrm{~s}$.

bleached state under illumination. It can be seen that a clear current impulse was obtained upon illumination. The current shoots up from near zero to $1.4 \mathrm{~mA}$ in $0.4 \mathrm{~s}$, then decays quickly in several seconds before getting stabilized. The time for $70 \%$ decrease $\left(t_{70 \%}\right)$ of the highest peak current is $6.4 \mathrm{~s}$, very closed to the response of transmittance change. Fig. 6(b) shows the in-situ transmittance response recorded at $780 \mathrm{~nm}$ from the bleached to colored state by applying a positive $2 \mathrm{~V}$ bias on $\mathrm{PB}$ electrode. The transmittance shows a fast decrease from $95 \%$ to $14 \%$ in less than one second. Fig. 6(c) shows the corresponding transient current change of this process, displaying a fast current decay. It can be seen that $t_{70 \%}$ of both the in-situ transmittance and transient current are $\sim 600 \mathrm{~ms}$, implying a fast electrochromic coloration response. The inset of Fig. 6(c) shows the charge involved during the coloration process by chronocoulometry. Corresponding to the current-time plot, charges are increased significantly in the first $10 \mathrm{~s}$, and then a linear increase with time is found for the following process. The electrochromic performance of the photoelectrochromic cell was also investigated by measuring its coloration efficiency $(C E, \eta)$ according to Fig. 6 (b and c). As it is 
a

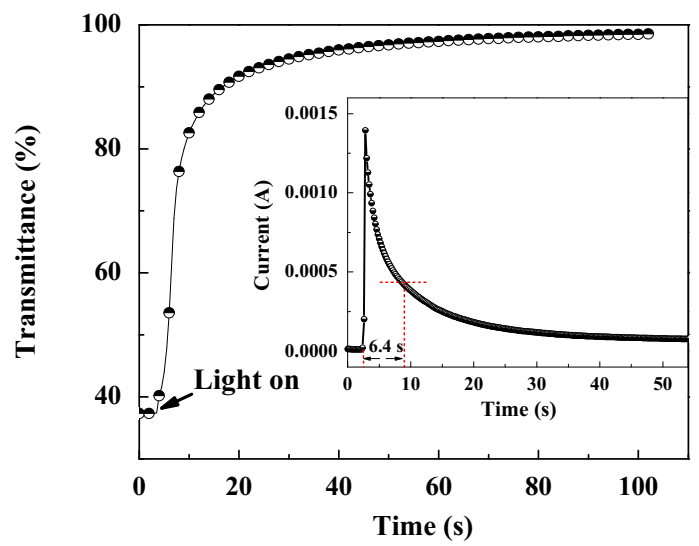

C

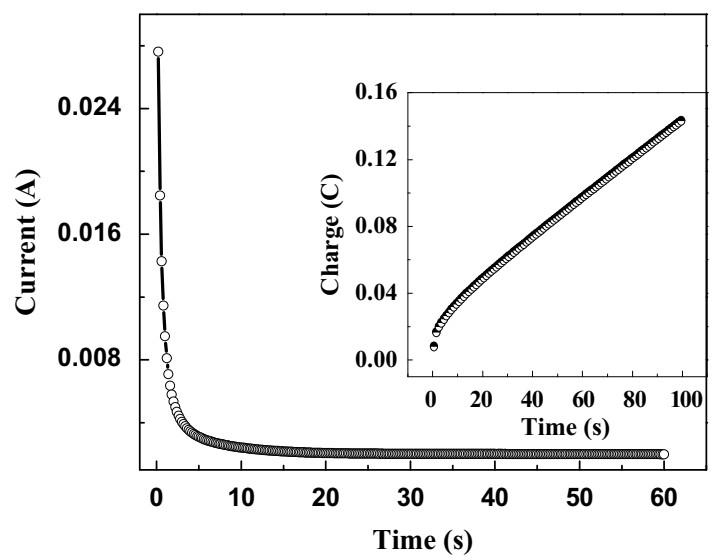

b

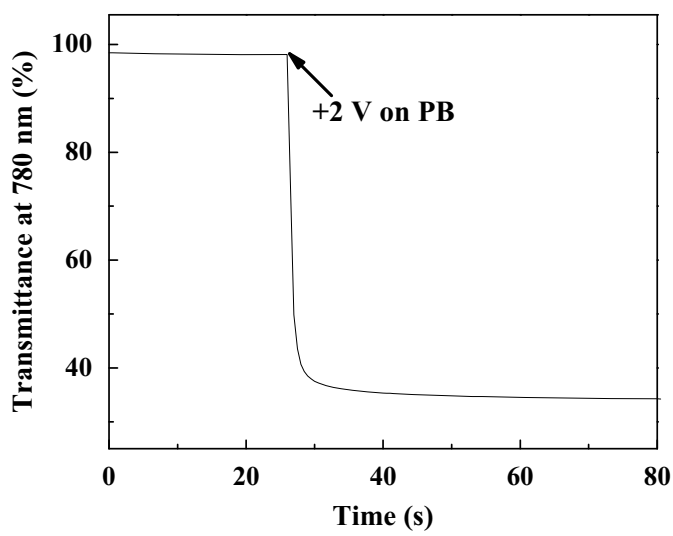

d

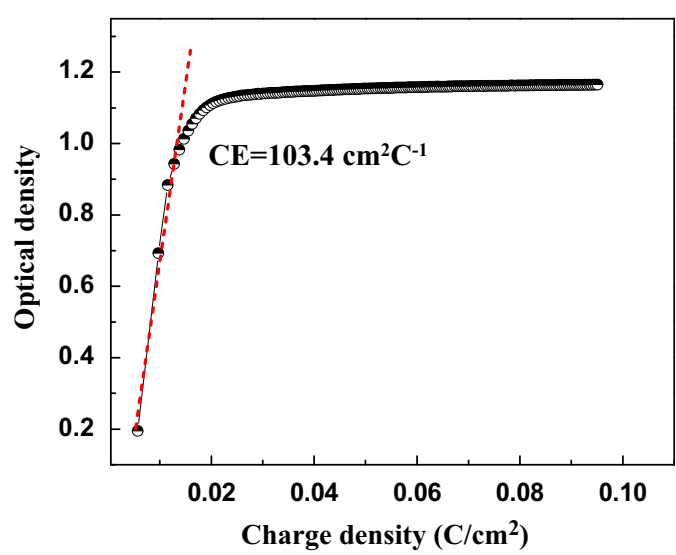

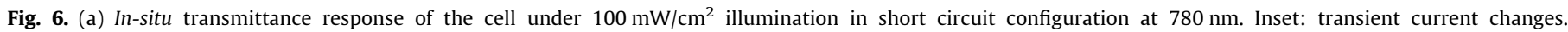

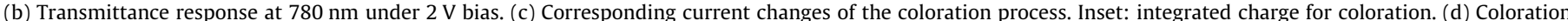
efficiency curve of the photoelectrochromic cell recorded at $780 \mathrm{~nm}$ with $2 \mathrm{~V}$ bias.

known, $C E$ represents the change in the optical density $(\triangle O D)$ per unit charge density change $(\Delta Q / A)$ during coloration or bleaching and can be calculated by Eqs. (4) and (5):

$\Delta O D=\log \left(T_{\text {bleach }}(\lambda) / T_{\text {color }}(\lambda)\right)$

and

$\eta=\Delta O D / \Delta Q / A$

where $T_{\text {bleach }}(\lambda)$ is the transmittance of the bleached state and $T_{\text {color }}(\lambda)$ is the transmittance of the colored state. $\Delta Q$ is the change of the charge consumed for the change in the optical density. The $C E$ of the photoelectrochromic cell recorded at $780 \mathrm{~nm}$ after adding a $2 \mathrm{~V}$ bias voltage is shown in Fig. $6(\mathrm{~d})$. The $C E$ was extracted as the slope of the line fitted to the linear region of the curve. The calculated $C E$ value is $103.4 \mathrm{~cm}^{2} / \mathrm{C}$ for our cell, which is comparable to the reported values [35].

The cell at colored state shows good stability in open circuit. While the photo-bleached cell gradually returns to colored state in either short circuit under dark state or open circuit with or without illumination, since the charged $\mathrm{Li}_{4} \mathrm{Fe}(\mathrm{II})_{4}\left[\mathrm{Fe}(\mathrm{II})(\mathrm{CN})_{6}\right]_{3}$ electrode possesses a negative potential that causes the cell to discharge spontaneously back to its colored state. Fig.7 shows the transmittance change of the cell in short circuit under dark and open circuit under illumination recorded at $780 \mathrm{~nm}$. The cell was photo-bleached under $100 \mathrm{~mW} / \mathrm{cm}^{2}$ illumination in short circuit configuration for $100 \mathrm{~s}$. It can be seen that the transmittance gradually decrease in either short or open circuit. Moreover, the short-circuited cell shows a faster decrease rate than that of the open-circuited one. The time for $30 \%$

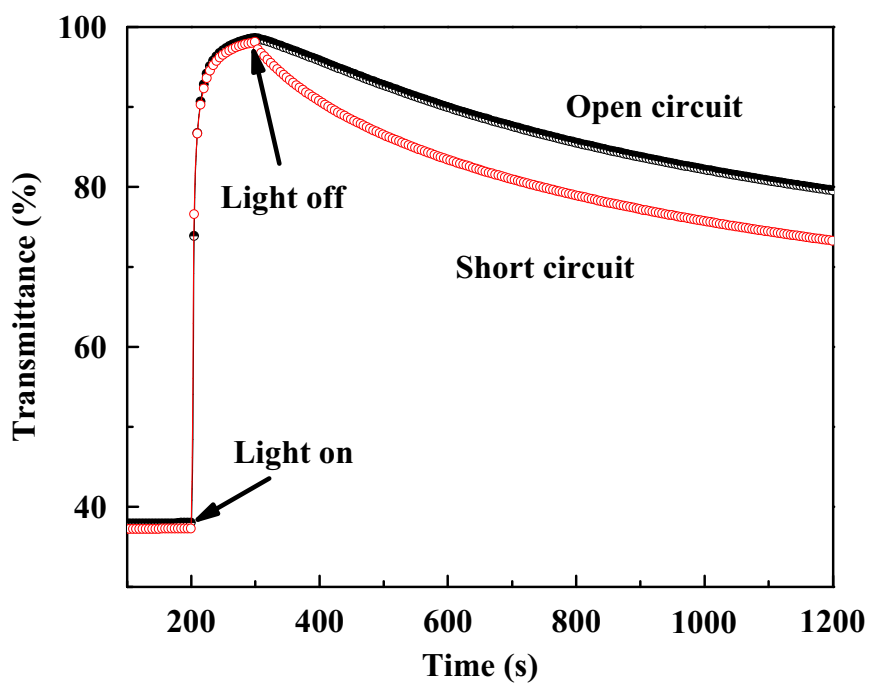

Fig. 7. Optical transmittance change versus time of the photoelectrochromic cell in short circuit under dark and open circuit under illumination. The cell was bleached under $100 \mathrm{~mW} / \mathrm{cm}^{2}$ illumination in short circuit configuration for $100 \mathrm{~s}$.

transmittance decrease are found to be $806 \mathrm{~s}$ and $505 \mathrm{~s}$ for opencircuited and short-circuited case, respectively.

The stability of the photoelectrochromic cell was also investigated by measuring the transmittance changes recorded at $700 \mathrm{~nm}$ between the bleached and colored states (Fig. 8). The 


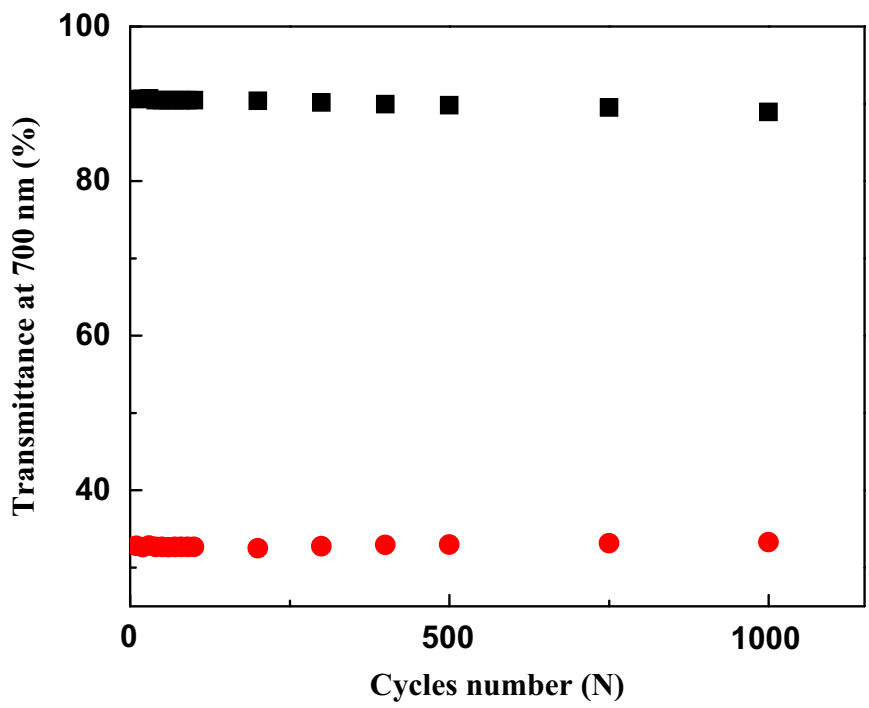

Fig. 8. Transmittance change $(\Delta T)$ at $700 \mathrm{~nm}$ as a function of cycle number of the photoelectrochromic cell, bleached under $100 \mathrm{~mW} / \mathrm{cm}^{2}$ illumination for $60 \mathrm{~s}$ and colored by adding a $2 \mathrm{~V}$ bias for $30 \mathrm{~s}$.

photo-bleaching process of the cell was conducted under $100 \mathrm{~mW} / \mathrm{cm}^{2}$ illumination in short circuit configuration for $60 \mathrm{~s}$ and the re-coloration was obtained by adding a $2 \mathrm{~V}$ bias on $\mathrm{PB}$ electrode for $30 \mathrm{~s}$. After 1000 cycles of operation, the performance of the cell is still quite stable. The transmittance attenuation was about $57.8 \%$ (from $90.6 \%$ to $32.8 \%$ ) of the first cycle, and after 1000 cycles, it had decreased to ca. $55.7 \%$ (from $88.9 \%$ to $33.2 \%$ ); only $2.1 \%$ optical degradation was found, indicating a good stability.

\section{Conclusions}

In conclusion, a fast-switching negative photoelectrochromic cell composed of dye-sensitized nanocrystalline $\mathrm{TiO}_{2}$ and $\mathrm{PB}$ electrodes was studied. Adjustable grayscales were obtained by illuminating the cell with different light intensity and time. The photo bleaching response of the cell at $100 \mathrm{~mW} / \mathrm{cm}^{2}$ is $6.2 \mathrm{~s}$, and the electrochromic response with a $2 \mathrm{~V}$ bias is about $600 \mathrm{~ms}$ for $70 \%$ transmittance change at $780 \mathrm{~nm}$ with electrochromic coloration efficiency of $103.4 \mathrm{~cm}^{2} / C$. This hybrid photoelectrochromic cell shows good stability and can be potentially applied in erasable displays.

\section{Acknowledgments}

The authors would like to thank the financial support from the Science and Engineering Research Council, Agency for Science, Technology and Research (A*STAR) of Singapore (Project nos. 092 1010057 and 092151 0088), Singapore NRF-RF-2009-09, and National Natural Science Foundation of China (NSFC) (Project nos. 61006037 and 61076015).

\section{Appendix. Supplementary materials}

Supplementary data associated with this article can be found in the online version at doi:10.1016/j.solmat.2011.10.030.

\section{References}

[1] C.M. Lampert, Electrochromic materials and devices for energy-efficient windows, Solar Energy Materials 11 (1984) 1-27.
[2] C.M. Lampert, Smart switchable glazing for solar energy and daylight control, Solar Energy Materials and Solar Cells 52 (1998) 207-221.

[3] C.M. Lampert, Electrochromics-history, technology, and the future, in: B.V.R. Chowdari, S.R.S. Prabaharan, M. Yahaya, I.A. Talib (Eds.), Proceedings of the Eighth Asian Conference on Solid State Ionics: Trends in the New Millennium, Langkawi, Malaysia, 2002, pp. 411-422.

[4] C.G. Granqvist, Oxide electrochromics: why, how, and whither, Solar Energy Materials and Solar Cells 92 (2008) 203-208.

[5] C.G. Granqvist, P.C. Lansaker, N.R. Mlyuka, G.A. Niklasson, E. Avendano, Progress in chromogenics: new results for electrochromic and thermochromic materials and devices, Solar Energy Materials and Solar Cells 93 (2009) 2032-2039.

[6] C.G. Granqvist, Electrochromic materials: out of a niche, Nature Materials 5 (2006) 89-90.

[7] M. Sun, N. Xu, Y.W. Cao, J.N. Yao, E.G. Wang, Nanocrystalline tungsten oxide thin film: preparation, microstructure, and photochromic behavior, Journal of Materials Research 15 (2000) 927-933.

[8] U.O. Krasovec, B. Orel, A. Georg, V. Wittwer, The gasochromic properties of sol-gel $\mathrm{WO}_{3}$ films with sputtered Pt catalyst, Solar Energy 68 (2000) 541-551.

[9] D. Schweiger, A. Georg, W. Graf, V. Wittwer, Examination of the kinetics and performance of a catalytically switching (gasochromic) device, Solar Energy Materials and Solar Cells 54 (1998) 99-108.

[10] V. Wittwer, M. Datz, I. Ell, A. Georg, W. Graf, G. Walze, Gasochromic windows, Solar Energy Materials and Solar Cells 84 (2004) 214-305.

[11] C. Bechinger, S. Ferrer, A. Zaban, J. Sprague, B.A. Gregg, Photoelectrochromic windows and displays, Nature 383 (1996) 608-610.

[12] B.A. Gregg, Photoelectrochromic cells and their applications, Endeavour 21 (1997) 52-55.

[13] H. Huang, L. Jiang, W.K. Zhang, Y.P. Gan, X.Y. Tao, H.F. Chen, Photoelectrochromic properties and energy storage of $\mathrm{TiO}_{2-x} \mathrm{~N}_{x} / \mathrm{NiO}$ bilayer thin films, Solar Energy Materials and Solar Cells 94 (2010) 355-359.

[14] H. Huang, S.X. Lu, W.K. Zhang, Y.P. Gan, C.T. Wang, L. Yu, X.Y. Tao, Photoelectrochromic properties of $\mathrm{NiO}$ film deposited on an $\mathrm{N}$-doped $\mathrm{TiO}_{2}$ photocatalytical layer, Journal of Physics and Chemistry of Solids 70 (2009) 745-749.

[15] G. Leftheriotis, G. Syrrokostas, P. Yianoulis, Development of photoelectrochromic devices for dynamic solar control in buildings, Solar Energy Materials and Solar Cells 94 (2010) 2304-2313.

[16] G. De Filpo, S. Mormile, F.P. Nicoletta, G. Chidichimo, Fast, self-supplied, all-solid photoelectrochromic film, Journal of Power Sources 195 (2010) 4365-4369.

[17] C.M. Lampert, Progress in switching windows, in: C.M. Lampert, C.G. Granqvist, K.L. Lewis (Eds.), Proceedings of the Conference on Solar and Switching Materials, SPIE-International Society for Optical Engineering, Bellingham, 2001, pp. 95-103.

[18] J.Y. Liao, K.C.J. Ho, A photoelectrochromic device using a PEDOT thin film, Journal of New Materials for Electrochemical Systems 8 (2005) 37-47.

[19] U.O. Krasovec, A. Georg, V. Wittwer, J. Luther, M. Topic, Performance of a solid state photoelectrochromic device, Solar Energy Materials and Solar Cells 84 (2004) 369-380.

[20] Y. Ohko, T. Tatsuma, T. Fujii, K. Naoi, C. Niwa, Y. Kubota, A. Fujishima, Multicolour photochromism of $\mathrm{TiO}_{2}$ films loaded with silver nanoparticles, Nature Materials 2 (2003) 29-31.

[21] T. Tatsuma, K. Suzuki, Photoelectrochromic cell with a $\mathrm{Ag}-\mathrm{TiO}_{2}$ nanocomposite: concepts of drawing and display modes, Electrochemistry Communications 9 (2007) 574-576.

[22] J.J. Wu, M.D. Hsieh, W.P. Liao, W.T. Wu, J.S. Chen, Fast-switching photovoltachromic cells with tunable transmittance, ACS Nano 3 (2009) 2297-2303.

[23] X.F. Yu, Y.X. Li, N.F. Zhu, Q.B. Yang, K. Kalantar-zadeh, A polyaniline nanofibre electrode and its application in a self-powered photoelectrochromic cell, Nanotechnology 18 (2007) 8.

[24] V.D. Neff, Electrochemical oxidation and reduction of thin-films of Prussian blue, Journal of the Electrochemical Society 125 (1978) 886-887.

[25] D.M. DeLongchamp, P.T. Hammond, High-contrast electrochromism and controllable dissolution of assembled Prussian blue/polymer nanocomposites, Advanced Functional Materials 14 (2004) 224-232.

[26] S. Hara, H. Tanaka, T. Kawamoto, M. Tokumoto, M. Yamada, A. Gotoh H. Uchida, M Kurihara, M. Sakamoto, Electrochromic thin film of Prussian blue nanoparticles fabricated using wet process, Japanese Journal of Applied Physics 46 (Part 2) (2007) L945-L947.

[27] A.A. Karyakin, Prussian blue and its analogues: electrochemistry and analytical applications, Electroanalysis 13 (2001) 813-819.

[28] U. Scharf, E.W. Grabner, Electrocatalytic oxidation of hydrazine at a Prussian blue - modified glassy carbon electrode, Electrochimica Acta 41 (1996) 233-239.

[29] A. Eftekhari, Potassium secondary cell based on Prussian blue cathode, Journal of Power Sources 126 (2004) 221-228.

[30] K. Itaya, T. Ataka, S. Toshima, Spectroelectrochemistry and electrochemical preparation method of Prussian blue modified electrodes, Journal of the American Chemical Society 104 (1982) 4767-4772.

[31] B. Oregan, M. Gratzel, A low-cost, high-efficiency solar-cell based on dyesensitized colloidal $\mathrm{TiO}_{2}$ films, Nature 353 (1991) 737-740.

[32] H.L. Yu, C.C. Hsiao, W.C. Liu, New apparatus for haze measurement for transparent media, Measurement Science and Technology 17 (2006) N29-N36.

[33] SAGE Electrochromics INC., 〈http://www.sage-ec.com >.

[34] EControl-Glas Gmbh, 〈http://www.econtrol-glas.de $\rangle$.

[35] L.C. Chen, Y.H. Huang, K.T. Hou, A complementary electrochromic system based on Prussian blue and indium hexacyanoferrate, Journal of the Solid State Electrochemistry 7 (2002) 6-10. 